\title{
Smart Alerts: Development of Software to Optimize Data Monitoring
}

\author{
Patrick Marcel Dherte ${ }^{1}$, Mariana Pires Gentil Negrão ${ }^{2}$, Silvio Mori Neto ${ }^{3}$, Rafael Holzhacker ${ }^{4}$, \\ Vanessa Shimada ${ }^{5}$, Paula Taberner ${ }^{6}$, Maria José Carvalho Carmona, TSA ${ }^{7}$
}

Summary: Dherte PM, Negrão MPG, Mori Neto S, Holzhacker R, Shimada V, Taberner P, Carmona MJC - Smart Alerts: Development of a Software to Optimize Data Monitoring.

Background and objectives: Monitoring is useful for vital follow-ups and prevention, diagnosis, and treatment of several events in anesthesia. Although alarms can be useful in monitoring they can cause dangerous user's desensitization. The objective of this study was to describe the development of specific software to integrate intraoperative monitoring parameters generating "smart alerts" that can help decision making, besides indicating possible diagnosis and treatment.

Methods: A system that allowed flexibility in the definition of alerts, combining individual alarms of the parameters monitored to generate a more elaborated alert system was designed. After investigating a set of smart alerts, considered relevant in the surgical environment, a prototype was designed and evaluated, and additional suggestions were implemented in the final product. To verify the occurrence of smart alerts, the system underwent testing with data previously obtained during intraoperative monitoring of 64 patients. The system allows continuous analysis of monitored parameters, verifying the occurrence of smart alerts defined in the user interface.

Results: With this system a potential $92 \%$ reduction in alarms was observed. We observed that in most situations that did not generate alerts individual alarms did not represent risk to the patient.

Conclusions: Implementation of software can allow integration of the data monitored and generate information, such as possible diagnosis or interventions. An expressive potential reduction in the amount of alarms during surgery was observed. Information displayed by the system can be oftentimes more useful than analysis of isolated parameters.

Keywords: Monitoring, Intraoperative; Clinical Alarms; Anesthesia; Software; Decision Support Systems, Clinical.

[Rev Bras Anestesiol 2011;61(1): 72-80] CElsevier Editora Ltda.

\section{INTRODUCTION}

Monitoring plays a fundamental role in following-up the evolution of anesthesia and in prevention, diagnosis, and treatment of adverse events. The minimal monitoring of one electrocardiographic derivation, blood pressure, and pulse oximetry, besides capnography in patients undergoing mechanical ventilation, is considered obligatory during anesthesia regulated by a specific medical legislation on the matter (CFM Resolution 1802/06).

Received from the Programa de Residência Médica em Anestesiologia do Hospital das Clínicas (HC) da Faculdade de Medicina (FM) da Universidade de São Paulo (USP) HCFMUSP, Brazil.

1. Electrical Engineer from Escola Politécnica da USP; Development Engineer at Dixtal

2. Electrical Engineer Student at Escola Politécnica of USP (Development Intern at Dixtal)

3. B.S, in Computer Sciences from Universidade Federal de São Carlos; Development Coordinator at Dixtal

4. M.Sc. in Engineering and Administration from the Massachusetts Institute of Technology: Electrical Engineer from Escola Politécnica da USP; Senior Manager of R\&D at Dixtal

5. MBA In Technological Knowledge and Innovation from Fundação Instituto Administração; Electrical Engineer from Escola Politécnica da USP; Manager of R\&D at Dixtal

6. M.D. of the Residency Program in Anesthesiology at HCFMUSP

7. M.D.; Associate Professor of the Anesthesiology Department of FMUSP; Director of the Anesthesia Department of Instituto Central of HCFMUSP.

Submitted on August 09, 2010.

Approved on August 12, 2010.

Correspondence to:

Dra. Maria José Carvalho Carmona

Divisão de Anestesia do ICHC

Av. Enéas Carvalho de Aguiar, 255 - 80 andar

Cerqueira César

05403-900 - São Paulo, SP, Brazil

E-mail: taberner@yahoo.com
Each monitor contains an alarm system, in general a sound and/or light, set to go off at different levels of severity when the data being monitored strays away from predetermined limits or whenever some flaw in the equipment is detected. Individual non-integrated alarms, more than being bothersome, tend to create acoustic chaos ${ }^{1}$ and they can compromise the quality and safety of patient care ${ }^{2}$.

Besides, several studies have shown a high rate of false alarms, which can be higher than $90 \% 2,3$. One study demonstrated that out of 1,455 alarms only 8 represented critical risk and potential risk to the life of the patient ${ }^{4}$. Another study suggested that alarms only indicate risk to the patient in $3 \%$ of the cases, and that in $75 \%$ of the case they are false alarms. This was demonstrated in a study in 50 different institutions ${ }^{5}$. One can infer from those studies that the majority of limit-based alarms have little or no impact in the care of critical patients ${ }^{2,3}$.

The large incidence of false alarms can result in dangerous desensitization of health care professional regarding true alarms ${ }^{3}$. One study suggests that even anesthesiologists frequently turn off the alarms due to the of unacceptably high incidence false alarms ${ }^{6}$. It is evident that alarm systems are in urgent need of improvement ${ }^{3}$.

The objective of the present study was to describe the development of "smart alert" software based on the integration of monitoring data during anesthesia and on a set of rules that can be adjusted by the anesthesiologist. Those alerts provide important information on patient status and possible risk situ- 
ations that are not clearly seen by the presence of individual alarms. This use of multiple variables can also be a way of eliminating false alarms, as shown by Ali et al. ${ }^{7}$.

\section{METHODS}

The present study was developed in a laboratory with simulation of monitoring data without specific investigation of patients. A specific software integrating data monitored and indicating possible diagnosis according to specific parameters or association of parameters was developed. This type of system may be considered a decision support systems, also known as Clinical Decision Support (CDS).

Any software developed to aid directly a clinical decision is a CDS system. In such systems individual patient characteristics are compared with a data base to generate alarms, checklists, and even possible diagnosis or interventions that are presented to the physician. Those systems can improve performance regarding medication doses, preventive treatments, and even diagnosis ${ }^{8}$. In fact, it is believed that those systems can increase the efficacy and improve the quality of patient care ${ }^{9}$. In a well known study in this area, Westenkow et al. ${ }^{10}$ demonstrated the effects of smart alarms in the response time of anesthesiologists although this type of system is not widely developed, since it requires knowledge in software and integration with the clinical field 5 .

The cycle of development of a technologic project includes the definition of requirements, development, verification of requirements (tests), and evaluation during use or in simulations ${ }^{10}$. An anesthesiology expert team from the Hospital das Clínicas, Faculdade de Medicina of Universidade de São Paulo was involved in the process and in the definition of the rules that would be used to configure the alarms after the system was ready. The team was also involved in validating the system in a simulated environment.

From the initial investigation of obligatory monitoring data, the expert team performed possible alarm integrations with clinical meaning. The software development team was in charge of implementing the system that analyses the data captured by the monitoring equipment and displays messages that support the decisions defined for each alert.

The prototype was evaluated by the expert team, and additional suggestions were integrated in the final product.

The system analyses continuously the set of monitored parameters, verifying the occurrence of alerts defined in the user interface, and it was designed to give the anesthesiologist flexibility in the definition of the alarms.

An alert is defined by one or more combined logic rules by "OR" and/or "AND" operators. On its turn, each rule is formed by one parameter, one comparison operator (greater than or smaller than), and a numerical value (e.g., heart rate $>100)$.

When an alert is formed by the combination of rules through the AND operator, the alert will be triggered when all rules are simultaneously fulfilled. In the case of the OR operator, at least one of the rules should be fulfilled to trigger the alert. The combination of operators allows great flexibility. The operator can also define a delay time for triggering the alert requiring the alert to be active for a given time to trigger the alert, therefore avoiding some false positives. Finally, the anesthesiologist should define the message to be displayed in the moment the alert is triggered.

During development patient simulators were used and the product underwent laboratorial testing with data from real surgeries to verify the occurrence of smart alerts in a surgical environment. For this, a database recorded during the study developed by Zamper et al. ${ }^{11}$ to validate a computer system to elaborate the anesthesia record was used. This database contains information on 64 real medium and large surgeries under general and regional anesthesia.

For each surgery, the number of smart alerts detected was compared to the amount of individual alerts triggered. For this, only the alarms of the parameters used in the alert definition were used.

\section{RESULTS}

Smart alerts used for these tests resulted from an investigation of the expert team and are depicted in Table I.

Analyzing the data of the set of 64 surgeries, one can notice that 514 alarms were triggered and only 39 smart alerts, which were for bradicardia and hypertension and tachycardia, representing a $92 \%$ potential reduction in the amount of alarms (Table II). Even considering the importance of critical alarms such as low $\mathrm{SpO}_{2}$ the association of this isolated alarm with the smart alarms allows a significant reduction in the total number of alarms. In 46 surgeries (72\%) no smart alerts were detected and among those surgeries only one (2\%) did not show alarms of isolated parameters, while the remaining 45 surgeries showed a total of 278 alarms, an average of 6 alarms per surgery. In 18 surgeries (28\%) 30 smart alerts were detected, an average of 2.17 alarms per surgery. In those surgeries, the occurrence of alarms was 236, an average of 13 alarms per surgery.

Among the cases evaluated, electronic anesthesia reports of nine cases of high risk patients were selected. The occurrence of simple alarms and smart alerts was analyzed to verify the conditions of their occurrence (Table III). We observed 119 situations of intraoperative alarms generated, 17 of them caused by a reduction in $\mathrm{SpO}_{2}$. Thirty-one situations that generated tachycardia alarms and 21 of hypotension were observed, although in only 9 conditions smart alerts indicating the association of tachycardia and hypertension were observed. On the other hand, among the 15 cases of alarms for bradycardia and 11 for hypotension in only one situation the alert for bradycardia associated with hypotension was observed. 
Table I - Alerts Considered for Adults

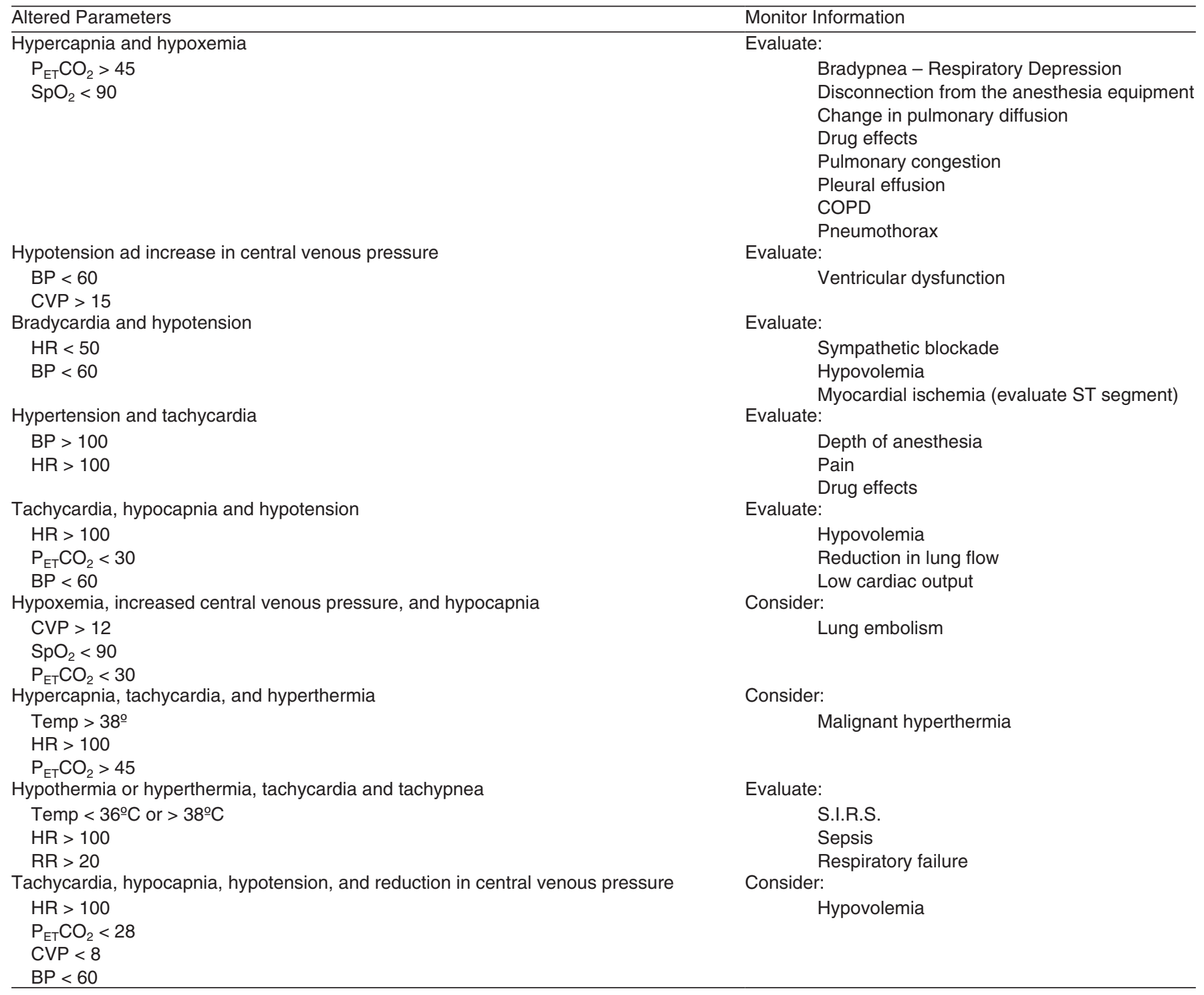

Table II - Number of Alarms and Smart Alerts

\begin{tabular}{|c|c|c|c|}
\hline & \multicolumn{2}{|l|}{ Surgeries } & Total \\
\hline \multicolumn{4}{|l|}{ Alarms } \\
\hline Hypertension (BP > 100) & 85 & 103 & 188 \\
\hline Hypotension $(\mathrm{BP}<60)$ & 18 & 44 & 62 \\
\hline Tachycardia $(H R>100)$ & 47 & 16 & 63 \\
\hline Hypercapnia $\left(\mathrm{P}_{\mathrm{ET}} \mathrm{CO}_{2}>45\right)$ & 10 & 7 & 17 \\
\hline Reduction in CVP (CVP < 8) & 4 & 0 & 4 \\
\hline Increase in CVP (CVP > 15) & 13 & 2 & 15 \\
\hline Tachypnea $(\mathrm{RR}>20)$ & 12 & 5 & 17 \\
\hline Total & 236 & 278 & 514 \\
\hline \multicolumn{4}{|l|}{ Smart alerts } \\
\hline
\end{tabular}


Table III - Number of Alarms and Smart Alerts in Nine Selected Surgeries

\begin{tabular}{|c|c|c|c|c|c|c|c|c|c|}
\hline Surgical Record & 115 & 127 & 54 & 57 & 69 & 79 & 89 & 94 & 97 \\
\hline \multicolumn{10}{|l|}{ Alarms } \\
\hline Hypertension (BP > 100) & 5 & 11 & 3 & 1 & 0 & 0 & 1 & 2 & 8 \\
\hline Tachycardia $(\mathrm{HR}>100)$ & 1 & 1 & 0 & 0 & 6 & 1 & 0 & 0 & 12 \\
\hline Bradycardia $(\mathrm{HR}<50)$ & 0 & 2 & 2 & 4 & 0 & 0 & 3 & 3 & 1 \\
\hline Hypocapnia $\left(\mathrm{P}_{\mathrm{ET}} \mathrm{CO}_{2}<30\right)$ & 0 & 0 & 0 & 0 & 1 & 0 & 0 & 0 & 0 \\
\hline Reduction in CVP (CVP < 8) & 0 & 3 & 0 & 0 & 0 & 0 & 0 & 0 & 1 \\
\hline Increase in CVP (CVP > 15) & 0 & 11 & 0 & 0 & 0 & 0 & 0 & 2 & 2 \\
\hline Tachypnea (FR > 20) & 0 & 0 & 0 & 0 & 0 & 0 & 0 & 0 & 0 \\
\hline Total & 8 & 30 & 5 & 5 & 19 & 4 & 5 & 8 & 35 \\
\hline \multicolumn{10}{|l|}{ Smart alerts } \\
\hline Bradycardia and hypotension & 0 & 0 & 0 & 0 & 0 & 0 & 0 & 0 & 1 \\
\hline
\end{tabular}

\section{DISCUSSION}

The present study presented a software to integrate all monitoring data and generate information on possible diagnosis and interventions. Those can be even more useful for the anesthesiologist when compared with the information provided by a single parameter.

Based on the literature and on the results of the present study, one can conclude that the enormous rate of false alarms in a surgical environment and the small significance of those alarms regarding patient care are responsible for those alarms to be disregarded or, at least, underestimated by the anesthesiologist.

In this context, one can realize that there is much to be done to improve the quality of information presented by the alarm system during follow-up of anesthesia. The use of CDS systems is one way of making the monitoring data more significant for the physician. Besides integrating monitoring clinical parameters, those systems can help decision making. This system allows compilation of anesthesiology knowledge in a series of rules that use simple logic. It also allows determination by the anesthesiologist of which rules will be adopted and which risk situations will be observed.

The first result obtained in this study was a table with possible logic combination of the levels of some parameters determined by a team of experts in the field.

The increase of quality in patient care due to the exhibition of messages of possible diagnosis is yet to be proven in patient studies.

We conclude that the system developed can be useful in the daily practice of the anesthesiologist, and information displayed by the system can be sometimes useful to analyze individual parameters. 


\section{REFERÊNCIAS / REFERENCES}

01. Hagenouw RR - Should we be alarmed by our alarms? Curr Opin Anaesthesiol, 2007;20:590-594.

02. Imhoff M, Kuhls S - Alarm algorithms in critical care monitoring. Anesth Analg, 2006;102:1525-1537.

03. Imhoff M, Kuhls S, Gather $\mathrm{U}$ et al. - Smart alarms from medical devices in the OR and ICU. Best Pract Res Clin Anaesthesiol, 2009;23:39-50.

04. O'Carroll TM - Survey of alarms in an intensive therapy unit. Anaesthesia, 1986;41:742-744.

05. Dunsmuir D, Daniels J, Brouse C et al. - A knowledge authoring tool for clinical decision support. J Clin Monit Comput, 2008;22:189-198.

06. Block Jr FE, Rouse JD, Hakala M et al. - A proposed new set of alarm sounds which satisfy standards and rationale to encode source information. J Clin Monit Comput, 2000;16:541-546.

07. Ali W, Eshelman L, Saeed M - Identifying artifacts in arterial blood pressure using morphogram variability. Comput Cardiol, 2004;31:697-700.

08. Hunt DL, Haynes RB, Hanna SE et al. - Effects of computer-based 
clinical decision support systems on physician performance and patient outcomes: a systematic review. JAMA, 1998;280:1339-1346.

09. John G, Peter JV, Chacko B et al. - A computer-assisted recording, diagnosis and management of the medically ill system for use in the intensive care unit: a preliminary report. Indian J Crit Care Med, 2009;13:136-142.

10. Westenskow DR, Orr JA, Simon FH et al. - Intelligent alarms reduce anaesthesiologist's response time to critical faults. Anesthesiology, 1992;77:1074-1079.

11. Zamper RPC, Torres MLA, Ferraz JL et al. - Avaliação de relatório eletrônico de anestesia. Rev Bras Anestesiol, 2010;60:285-301.

Resumen: Dherte PM, Negrão MPG, Mori Neto S, Holzhacker R, Shimada V, Taberner P, Carmona MJC - Alertas Inteligentes: Desarrollo de un Software para la Optimización de los Datos de Monitorización.

Justificativa y objetivos: La monitorización es útil en el seguimiento de los parámetros vitales y en la prevención, diagnóstico y tratamiento de eventos adversos en anestesia. Las alarmas, aunque sean útiles en la monitorización, pueden causar una peligrosa desensibilización del usuario. Aquí hemos querido describir el desarrollo de un software específico para la integración de los parámetros de monitorización intraoperatoria, generando "alertas inteligentes" que puedan ayudar en la toma de decisiones, además de indicar posibles diagnósticos y tratamientos.

Método: Se proyectó un sistema que permitiese la flexibilidad en la definición de las alertas, combinando las alarmas individuales de los parámetros monitorizados para generar una alerta más elaborada. Posteriormente a la investigación de un conjunto de alertas inteligentes consideradas relevantes en el ambiente quirúrgico, se obtuvo y se evaluó un prototipo, y las sugerencias adicionales fueron implementadas en el producto final.

Para la verificación de la incidencia de las alertas inteligentes, el sistema fue sometido a pruebas con datos previamente obtenidos durante la monitorización intraoperatoria de 64 pacientes. El sistema desarrollado permite un análisis continuo del conjunto de parámetros monitorizados verificando el surgimiento de las alertas inteligentes definidas en la interfaz del usuario.

Resultados: Con el uso del sistema, verificamos un potencial de reducción de las alarmas en el umbral del 92\%. Notamos también, que en la mayoría de las situaciones en que no fueron generadas alertas, las alarmas individuales no representaban situaciones de riesgo para el paciente.

Conclusiones: La implementación de herramientas de software pueden posibilitar la integración de los datos de monitorización y generar informaciones como posibles diagnósticos o intervenciones. Se verificó una reducción potencial expresiva en la cantidad de alarmas durante la anestesia. Las informaciones que el sistema mostró pueden ser algunas veces más útiles que el análisis de parámetros aislados.

Descriptores: COMPUTADOR, Ingeniería de software, CDS; EQUIOS: Alarmas Clínicos; MONITORIZACIÓN, Intraoperatório. 